Theory

\title{
Person-Situation Navigation Mechanisms at Work
}

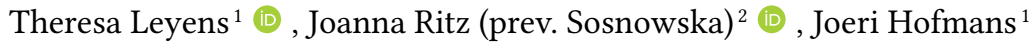 \\ [1] Department of Work and Organizational Psychology, Vrije Universiteit Brussel, Brussels, Belgium. [2] Amsterdam \\ Business School Leadership and Management, University of Amsterdam, Amsterdam, Netherlands.
}

Personality Science, 2021, Vol. 2, Article e7169, https://doi.org/10.5964/ps.7169

Received: 2021-07-16 • Accepted: 2021-12-06 • Published (VoR): 2021-12-23

Handling Editor: Marco Perugini, University of Milan-Bicocca, Milan, Italy

Reviewing: Round 1 - Anonymous \#1; Anonymous \#2. Open reviews are available. [see Index of Supplementary Materials]

Corresponding Author: Theresa Leyens, Vrije Universiteit Brussel, Pleinlaan 2, 1050 Brussel, Belgium. E-mail: theresa.leyens@vub.be

\begin{abstract}
Rather than focusing on their dynamic interplay, research in I/O psychology has mostly focused on either person-level variables as predictors of work behaviors or the impact of situational variables on employees' behaviors. By studying person and situation variables independently or by treating the situation as fixed, previous studies have largely failed to capture the active role employees take in affecting and managing their work situations. This raises the question of how adequately current research that focuses on either the person or the situation captures the reality of work life. To address this issue, this paper aims to provide a starting point for the integration of personsituation interactions at work into an overarching process model (i.e., Person-Situation Navigation Mechanisms Framework; Rauthmann \& Sherman, 2016), and illustrates how previous research on $\mathrm{I} / \mathrm{O}$ constructs can be positioned within this framework.
\end{abstract}

\section{Keywords}

person-situation interactions, person-situation navigation mechanisms, situation management strategies, personality dynamics 


\section{Relevance Statement}

We call for explicit attention to person-situation navigation mechanisms at work. As a first step, we provide an overarching person-situation navigation process model and illustrate how several I/O constructs can be positioned within this framework.

\section{Key Insights}

- Employees engage with their work environment through situation management.

- Situation management pertains to a series of intertwined strategies.

- Individual work situations result from ongoing dynamic person-environment interactions.

- Situations cannot be studied independently from individuals experiencing them.

Although most Industrial and Organizational (I/O) psychologists implicitly or explicitly acknowledge that persons and the situations they find themselves in interact in complex ways, the dynamic interplay between persons and situations has received relatively little scholarly attention. ${ }^{1}$ Rather than focusing on their dynamic interplay, research has typically focused on person-related variables as predictors of work behaviors or how situational variables impact employees' behaviors. Moreover, studies that have adopted an interactionist perspective tend to conceptualize the situation as something fixed by either examining individual differences in how people react to situations they are confronted with (using frameworks such as the Cognitive-Affective Processing System model of personality by Mischel \& Shoda, 1995, 1998) or how the situation people find themselves in allows for the expression of trait-relevant behaviors (using frameworks such as Trait Activation Theory by Tett \& Burnett, 2003; Tett et al., 2021).

By studying person and situation variables independently or by treating the situation as fixed, previous studies have largely failed to capture the active role employees take in affecting and managing their work situations. This in turn has limited our understanding of the many ways in which employees can mold their perceptions, cognitions, emotions, motivations, and behaviors at work. As a case in point, occupational health psychologists have paid a lot of attention to studying how employees react to stressful circumstances at work, and although this perspective is useful for understanding stress-related processes, this approach tends to conceptualize stressors as fixed, unchangeable demands that exist in the outside world, waiting for employees to be affected by them (e.g., Schaufeli, 2017; Xanthopoulou et al., 2007). The consequence is that those studies fail to take into account that employees typically go to great lengths to select, avoid or even try to change these stressful circumstances. This is surprising, particularly because one of the dominant

1) In this work, „interaction“ refers to reciprocal action or influence in the literal way, meaning that both person and situational factors jointly shape a person's behavior. 
frameworks in I/O psychology is the Person-Environment Fit framework (P-E fit; KristofBrown et al., 2005). The core idea of P-E fit is that a good fit between attributes of the person (e.g., values, skills, interests) and attributes of the environment (e.g., values, job requirements) is associated with positive individual outcomes and beneficial work outcomes (e.g., wellbeing and satisfaction, performance, and turnover; Kristof-Brown et al., 2005; van Vianen, 2018). In an effort to maximize fit, people's skills, qualities, and interests lead them to employ situation management strategies. For example, they select and craft jobs so that they fit their interests and skills (e.g., Etzel \& Nagy, 2021; Hanna et al., 2021), or they might quit their job when they experience a huge misfit in terms of values (e.g., Kristof-Brown et al., 2005). In that sense, Person-Environment fit can be seen as an important driving mechanism and motivation to engage in person-situation navigation mechanisms (Kandler \& Rauthmann, 2021).

In response to the lack of attention to this important issue, we call for explicit attention to person-situation navigation mechanisms at work, or the reciprocal feedback loops between employees and their situations. Admittedly, such reciprocal relations between persons and situations have been acknowledged in several lines of I/O research already, including the work on task-contingent personality (Minbashian et al., 2010), organizational citizenship behavior (Green et al., 2019), and work motivation and behavior (Judge et al., 2014). However, empirical studies on these topics have typically focused on (merely statistical) interactions (i.e., person-situation transactions; see Rauthmann, 2021) in very specific domains and contexts, without connecting this to the broader concept of person-situation relations. In the present paper, we stress the need to integrate these efforts into an overarching person-situation navigation process model, which would allow for knowledge cumulation on how people (over time) influence and manage their work situations. The goal of this paper is to provide a starting point for such integration by 1) advancing such process model that can be used towards this end (Rauthmann, 2021; Rauthmann \& Sherman, 2016), and 2) illustrating how previous research on I/O constructs can be positioned within this framework.

In particular, we will build on the Person-Situation Navigation Mechanisms Framework (Rauthmann, 2021; Rauthmann \& Sherman, 2016), in which different person-situation interactions - the so-called situation management strategies (construal, maintenance, selection, evocation, modification, creation; see Figure 1) - are systematized and compared. We argue that, in order to advance our knowledge of the complex ways people interact with situations at work, we need a clear understanding of 1) what person-situation interactions at work are, 2) how previous research fits within such a framework (see Table 2), and 3) future ways to systematically study I/O constructs in view of the Person-Situation Navigation Mechanisms Framework. This includes explanations of the different interaction mechanism categories, illustrations of examples that fall within each category, as well as gaps in the existing literature. Using the Person-Situation Navigation Mechanisms model (Rauthmann \& Sherman, 2016) as an overarching framework and 
integrating I/O research into the model might shed new light on the way people engage with situations in the context of work. In that sense, the present work is not so much an extension of Rauthmann and Sherman's (2016) framework, but rather uses the model to create order in the variety of findings that previous research in work and organizational psychology made. Further, the present paper also hopes to set a research agenda for future $\mathrm{I} / \mathrm{O}$ research.

\section{Conceptualization of Person-Situation Navigation Mechanisms at Work}

Just like in their private life, people at work are not randomly or passively exposed to situations. Instead, they have a certain degree of control over many of their work experiences. In other words, employees do - to some degree - select, avoid, alter, influence, and/or create the situations around them (Rauthmann, 2021; Rauthmann \& Sherman, 2016; Tett et al., 2021). These person-situation interactions can be understood as a series of conscious or unconscious situation management strategies that allow people to handle situations by experiencing or shaping them differently. ${ }^{2}$

In the present paper, we conceptualize these situation management strategies according to the framework of Rauthmann and Sherman (2016; see also Rauthmann, 2021). Following this framework, situational management strategies can be differentiated based on 1) intentionality (voluntarily and deliberate actions vs. involuntary and unconscious actions), 2) required effort of the person managing the situation, 3) control given to the person managing the situation, and 4) (physical) activity of the person managing the situation. The type of situation management strategy that is then adopted at a particular point in time is a function of how the situation is perceived by the employee and the employees' perceived options regarding their mental and/or behavioral reactions. For example, if a particular situation is perceived as positive, people tend to use a maintenance management strategy that allows them to passively remain in the situation or actively preserve the situation. In contrast, in case of a situation being perceived as negative, the employee may resort to reappraising (i.e., reconstruing) the situation, shaping the situation into a different one, leaving it entirely and selecting a new situation, or somehow evoking or creating a new situation (see Figure 1). Based on this situation management decision tree model, Rauthmann and Sherman (2016) differentiate between six main person-situation interaction mechanisms (referred to here as situation manage-

2) Note for the sake of completeness that external factors also play a role in the process of situation management: a high school diploma that allows studying a certain subject and applying for that one dream job, or financial security that allows taking on a riskier job, for example. It is therefore crucial to understand that not everything can always be actively managed, and that external circumstances also play a role. 
ment strategies), namely construal, maintenance, selection, evocation, modification, and creation.

Before we proceed, it is important to stress that, when using the term "situation" we refer to a variety of situation-like concepts ranging from micro-level occurrences to macro-level contexts. Drawing on Rauthmann and Sherman (2020, based on Rauthmann et al., 2015), we differentiate between five situation-like concepts that can be distinguished on the basis of their duration, stability, and abstraction. The example shown in Table 1 illustrates those differences: a new colleague is greeted by a co-worker (occurrence) at a welcoming event (situation). The new colleague is being introduced to everyone and offered some finger food (episode). This takes place within a department of a large company at the companies' office building (environment) in Belgium at the 21st century (context).

\section{Table 1}

Overview of Different Situation-Like Concepts

\begin{tabular}{ll}
\hline Term & Example \\
\hline Occurrence & Being greeted by co-worker \\
Situation & Welcoming event at new firm \\
Episode & Being introduced and offered some snacks \\
Environment & Company department; colleagues \\
Context & Belgium; 21st century \\
\hline
\end{tabular}

Note. Adapted from Rauthmann et al. (2015), Table 2; Rauthmann \& Sherman (2020), Table 1.

Importantly, the mechanisms from the Person-Situation Navigation Framework apply across those different levels. In other words, people construct, maintain, select, evocate, modify, and create their experiences on micro- and macro-levels. For example, while an employee selecting into a new job happens on the environmental level (i.e., the macro level with considerable duration, stability, and abstraction), an employee starting a chat with a co-worker in the hallway pertains to situation selection at the level of an occurrence (i.e., short duration, stability, and low abstraction). Due to this, we use the term "situation" as the representative of this broader category of situation-like concepts in the remainder of this paper.

In what follows, we will discuss each of the situation management strategies. Moreover, we illustrate each strategy using an example from the I/O field, hence applying the Person-Situation Navigation Mechanisms Framework to work-related research. These examples range from occurrences (i.e., micro-level) to environmental features (i.e., macro-level), thereby illustrating that people actively shape what's happening around in all kinds of circumstances, with different consequences and motivations behind it. 


\section{Figure 1}

A Synopsis of Situation Management Strategies

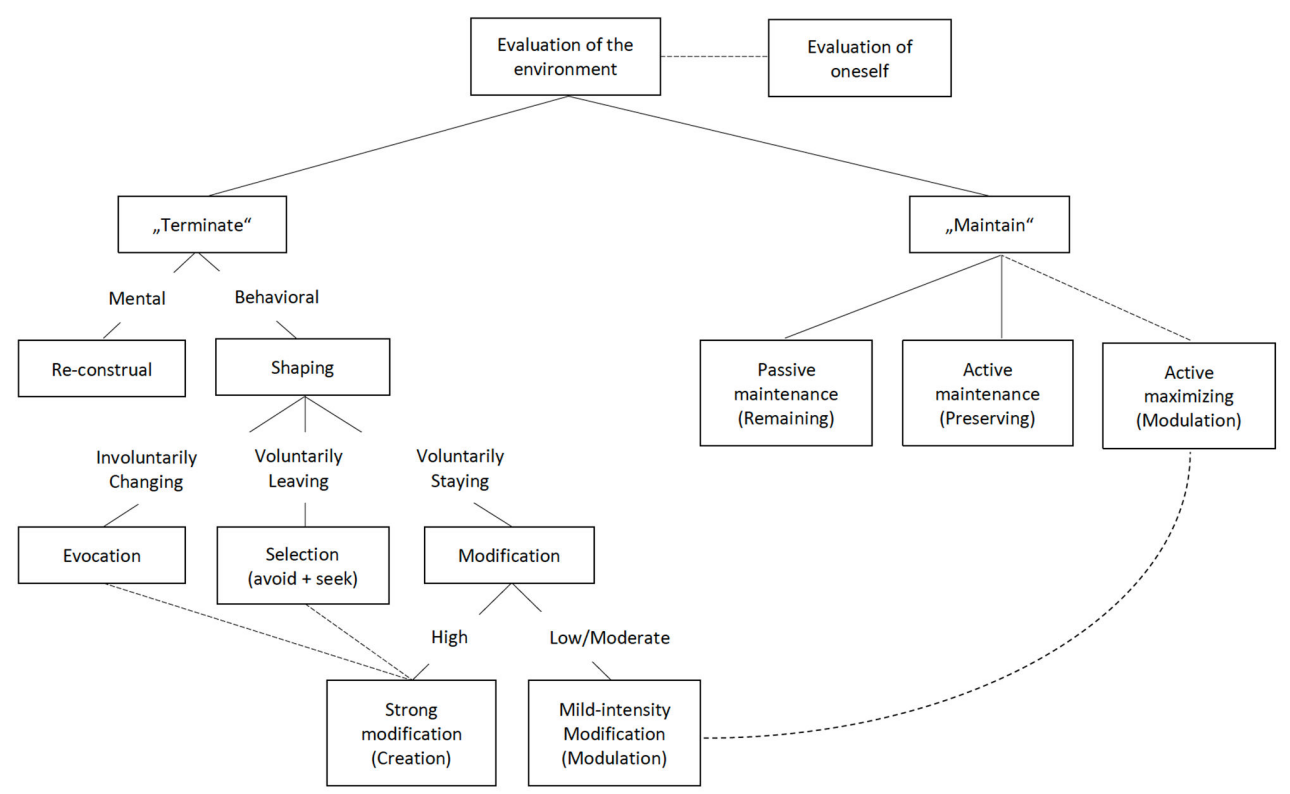

Note. Taken from J. F. Rauthmann, (2021). Retrieved from https://osf.io/ds6mw/ (CC-BY 4.0 licence).

Note that it is not our ambition to provide an exhaustive overview. We rather want to showcase how previous research within the I/O field (unknowingly) fits with such framework.

\section{Taxonomy of Situation Management Strategies}

\section{Construal}

People perceive situations at work differently. The same situation can be construed differently by different employees depending on their values, goals, and motives, which might all trigger unintentional and automatic construal schemes. Next to this automatic route, employees can also actively and intentionally change the way they perceive the situation (i.e., cognitive restructuring mechanisms). Regardless of the route taken, situation construal is extremely important because "To understand or to predict behaviour, the person and his environment have to be considered as one constellation of interdependent factors" (Lewin, 1946, p. 792). In other words, understanding the way employees 
perceive the situation is important because those idiosyncratic interpretations are critical for understanding consequent employee behaviors and emotions (Rauthmann, 2012).

Because I/O psychology is an applied in nature, many studies happen outside of the lab. The direct consequence is that many studies in I/O psychology tend to look at situations through the eyes of-or construed by-the employees experiencing them (e.g., Edwards \& Templeton, 2005; Sherman et al., 2010). Although this is understandable from a practical point of view, an important implication of this approach is that those studies do not allow separating the "objective" stimuli in the environment (e.g., meeting your supervisor in the hallway) from the subjective construal of that environment (e.g., how you perceive the way your supervisor greets you in the hallway). For example, in the Work Stress Questionnaire (Frantz \& Holmgren, 2019) participants are asked to rate statements such as "Does your supervisor consider your views?" or "Do you put high demands on yourself at work?". These ratings obviously tap into the psychological situations that employees experience at work, or how employees perceive their work environment. However, often those data are also used to then tweak the "objective situation" (i.e., objectively existing circumstances within the organization). For example, based on the survey's results interventions might be implemented on an organizational level, such as changing remuneration plans or working with flexible working hours. The lack of a clear distinction between objective and construed aspects of a situation might jeopardize those interventions in the sense that the company's proposed solutions might not be optimal, simply because the actual environment might not correspond to how the environment is perceived. Future research might aim to close this gap by paying more attention to how situations are construed by employees, which might in the long term increase the effectiveness of organizational interventions. One step in this direction has been taken by Ziegler et al., (2019) who measured construal (or situation perception) as a person-level variable. Measuring individual differences in the tendency to perceive situations in a specific way then allows separating idiosyncratic tendencies of situation perception from characteristics of momentary situations, and might be one step forward to disentangling the complex interplay between persons and situations.

\section{Maintenance}

This strategy refers to remaining actively or passively in the situation and, consequently, inhibiting change. Although fostering the stability of a situation (e.g., preserving the organizational culture) tends to be effortless and passive, in some circumstances it may require active resistance against change (e.g., resistance against re-structuring measures within a company). Depending on their personality predispositions, some people may be naturally inclined to preserve the stability of the situations they are in (e.g., individuals scoring low on Openness to Experience; see McCrae \& Costa, 1987). Employment of this strategy is also linked to employees' values and goals. This might for example be the case when individuals score high on values such as conformity and tradition or when an 
employee chooses to maintain an organizational culture that is coherent with their own values.

An example of situation maintenance in the I/O literature is resistance to organizational change. While early studies on the topic have looked at either individual or environmental triggers of such resistance, researchers are now starting to focus on the interaction of person and situation in predicting employees' reactions to organizational change (Oreg, 2006; Wanberg \& Banas, 2000). Oreg (2006), for example, found resistance to organizational change to stem from a dynamic interaction between numerous person and environmental factors. Moreover, he also emphasized the multidetermined nature of resistance to organizational change by making a distinction between goal-oriented situation maintenance and sustaining a situation because one doesn't like change (regardless of the respective change to happen; Oreg, 2006). Positioning resistance to organizational change within the Person-Environment Navigation Mechanisms Framework is useful because in the framework it is explicitly acknowledged that situation maintenance can be achieved in multiple ways: while we typically focus on active maintenance (preserving), the framework also acknowledged passive maintenance (remaining) and active maximizing (modifying). Although the literature on resistance to organizational change has primarily focused on preserving as a way of situation maintenance, complementing this perspective with passive (remaining) and even more active (modifying) approachesand the motivational mechanisms underlying those approaches-would allow for a more accurate knowledge cumulation on change behavior in a work context. Moreover, exploring and understanding situation maintenance as the result of the interplay between people at work and their occupational environment could also be beneficial for managers and HR practitioners, who might then implement change processes at work in a more efficient and purposeful way.

\section{Selection}

People can actively choose the situations they would like to participate in, while they can also actively avoid certain situations at work. The process of situation selection can be intentional (i.e., deliberately choosing the situation), while in other cases situations can naturally evolve into other situations (i.e., selection/avoidance without active deliberation). Situation selection and avoidance are driven by one's personality predispositions, which is, for example, shown by more extraverted people initiating social situations or agreeable people initiating conversations characterized by positive interpersonal features (Frederickx \& Hofmans, 2014).

In a work context, situation selection has often been studied in the capacity of job-search behavior, with research showing that people tend to self-select into jobs that fit their personality (Denissen et al., 2014; Wille \& De Fruyt, 2014). Indeed, the attraction-selection-attrition (ASA) hypothesis holds that job applicants tend to accept or deny job offers depending on whether or not their values and priorities match those 
of the respective organization (De Cooman et al., 2009). Job search behavior is typically considered to be goal-directed, driven by motivational tendencies and intentional in nature (Carless, 2005). This rationale aligns with the assumption underlying the Person-Environment Navigation Mechanisms Framework that individuals are not merely exposed to situations, but actively "deal with, navigate in, and govern their daily situations" (Rauthmann \& Sherman, 2016, p. 12).

While selection as a situation management strategy has primarily been studied in the context of major events like job choice behavior, situation selection also applies to minor events that happen continuously during everyday working routines. These ongoing situation selection processes have for example previously been associated with the experience of stress and, consequently, with psychological well-being (Bolger \& Schilling, 1991). Hence, studying situation selection at work has the potential to advance our understanding of how the interplay of individual predispositions and situational factors relates to ongoing decision-making processes in a work context. Once again, situation selection not only happens in case of long thought-out decisions like career choice behavior (i.e., environment, see Table 1; Carless, 2005), but it operates continuously in everyday processes, where people in a work context constantly steer through work life (i.e., occurrences; see Table 1; Bolger \& Schilling, 1991). In this context, Kandler and Rauthmann (2021) introduced the idea of P-E fitting, which pertains to the process of repeated interactions between personal dispositions and environments over time with the goal to increase the fit between the individual and the environment. This idea is supported by empirical research (e.g., Etzel \& Nagy, 2021; Hanna et al., 2021) showing that, as a result of ongoing person-situation interactions (and selection in particular), people gravitate towards a more optimal fit in the long run. ${ }^{3}$

\section{Evocation}

Unintentional elicitation of situations is captured by evocation, which refers to the creation or adaption of situations without any plan or intention to do so. This happens, for example, when an individual's behavior triggers changes in situational characteristics or in other people's behavior. Evocation typically requires very little effort and control because the situational change is triggered by factors outside of the individual's control. In any social context, people's behaviors trigger behavioral responses of others, which, in turn, elicit changes in situations. Unintentional changes in situations are therefore a common occurrence in the workplace, especially when other people are involved. However, evocation in the workplace has, to our knowledge, received little to no scholarly attention in $\mathrm{I} / \mathrm{O}$ psychology until now.

3) Importantly, Kandler and Rauthmann (2021) argue that P-E fitting not only draws on situation selection, but relies on all situation management strategies from the Person-Situation Navigation Mechanisms framework. 
Recognizing the evocative potential of work behaviors is of great importance. This is because some behaviors give other people more degrees of freedom for their behavior, and with that comes an increased chance of unintended (elicited) behaviors and their consequences. In a work context, laissez-faire leadership offers particularly high evocative potential. This passive leadership style describes a state in which someone physically occupies a leadership position but largely abdicates the responsibilities and duties assigned to it, thereby leaving group members in charge of decisions (Lewin et al., 1939; Skogstad et al., 2007). A passive management style leaves a lot of room for things outside of the leader's control - both positive and negative-to happen. Conversely, highly precise behaviors aiming to steer and control others (or the environment) offer less evocative potential - which does not imply that something unexpected is not evoked anyway, but merely that the variety of what can be evoked decreases. This would be the case for more active and controlling leadership styles, where a leader monitors and controls outcomes and clarifies roles and tasks clearly, thereby trying to control the situation instead of the other way around (Antonakis et al., 2003; Bass et al., 2003).

At present, evocation is largely neglected in the $\mathrm{I} / \mathrm{O}$ field in the sense that most $\mathrm{I} / \mathrm{O}$ research departs from the implicit assumption that what people do (at work) is intentional, and that people typically understand the possible consequences of their (intentional) behavior. While this may be true for some behaviors, it is far from complete. When studying evocation as a situation management strategy, one can distinguish between the evocative potential (i.e., the things that can happen [unintentionally] that you cannot control) of different work behaviors, the variety of evoked responses, the likelihood of evocation, the frequency of evocations across time, and the intensity of the responses evoked. Studying evocation using such nuanced approach is important because otherwise the conclusion would be that, in principle, any behavior could be evocative - although this is far from the truth.

\section{Modification}

People can intentionally change the existing situation into something different, and they often do so as part of a broader goal achievement strategy. Modification of the situation differs from evocation in the sense that it requires willingness and effort to change the existing conditions. As a consequence, a high degree of control and activity are necessary to modify a situation. Actively and purposefully changing something about the situation that is perceived as negative, or at least not desirable, is an important way in which employees can proactively improve their work experiences.

In a work context, situation modification might pertain to changing either the content of one's work responsibilities or the approach taken to fulfil those duties. In I/O psychology, such modification of the work situation is for example studied in the form of job crafting: self-initiated change behaviors that employees engage in, with the aim to align their jobs with their preferences, motives and passions (Berg et al., 2013). ${ }^{4}$ Crafting 
behaviors have been shown to have a positive impact on employees' well-being, leading to beneficial employee outcomes such as high engagement and job satisfaction (Tims et al., 2013). Although the body of literature on job crafting is substantial already, positioning job crafting in the broader framework of situation management strategies might allow for a better understanding of the motivational mechanisms behind the process. That is, according to Rauthmann and Sherman's (2016) situation management taxonomy, situation modification primarily happens in case the situation or specific situational aspects are perceived as negative (rather than positive) and if the situation cannot be terminated. Placing job crafting in a broader framework of situation management strategies thus explicates the conditions under which job crafting is more likely to happen. In addition, it positions job crafting as one strategy out of a set of strategies aimed at improving one's work experiences.

\section{Creation}

Finally, people can actively and intentionally create new situations. This often occurs in order to pursue goals or adhere to the values of either the individual or the organization. Creation, as opposed to modification, does not demote or modify an already existing situation, but creates an entirely new one. Therefore, this strategy requires a high level of effort, resources and control over the creative process.

In $\mathrm{I} / \mathrm{O}$ psychology, employees' engagement in extra-role behaviors is an example of situation creation at work. Extra-role behaviors are voluntary employee behaviors that are outside of the typical set of work responsibilities specified in one's work contract. Those extra-role behaviors might take the form of positive behaviors such as organizational citizenship behaviors (LePine et al., 2002; Miles et al., 2002), by which employees support the effective functioning of the organization outside of the formal requirements of their job (e.g., helping a colleague out). Conversely, the newly created situations can also be negative from the perspective of the organization. Such instances are referred to as counterproductive work behaviors (Dalal, 2005; Spector \& Fox, 2002), pertaining to employees' behaviors that go against the interest of the organization (e.g., theft, absenteeism). A more holistic view of situation creation at work, as part of a dynamic person-environment relation taxonomy, could provide important insights into the circumstances that lead people to display extra-role behavior. For example, according to Rauthmann and Sherman's (2016) situation management taxonomy, extra-role behavior will primarily show when employees are high in resources and when they have a sense of control over their own actions (see also Spanouli \& Hofmans, 2016). Such

\footnotetext{
4) In previous work (e.g., Wrzesniewski \& Dutton, 2001; Zhang \& Parker, 2019) different sub-categories of job crafting have been identified. One of those sub-categories is "cognitive job crafting", which pertains to employees altering how they frame or perceive their job (Zhang \& Parker, 2019). As a consequence, cognitive job crafting is an example of situation construal rather than situation modification.
} 
understanding can serve as a basis for companies to create caring, supportive work environments, therefore living up to their part of supporting employees beyond the formal requirements. Moreover, acknowledging the complex interplay between individual and environmental factors also means that organizations cannot expect employees to not display any counterproductive work behaviors, but rather emphasizes that employees act in response to situational and personal circumstances (Spector \& Fox, 2010). Exploring creation as an interactional situation management strategy between person and work environment factors thus allows to gain deeper insights into employees' behaviors towards their organization, both positive and negative.

Table 2

Situation Management Strategies (Rauthmann \& Sherman, 2016) in Previous Research

\section{Situation management strategy/}

Description

\section{Construal}

Perceiving a situation (potentially differently from how others perceive it)

\section{Maintenance}

Remaining in and maintaining a situation

\section{Selection}

Actively choosing situations to avoid or participate in

\section{Evocation}

Engendering certain situations without specific intentions of doing so

\section{Modification}

Actively modulating an existing situation Job crafting into something different

Job-Demands Resources model

Schaufeli (2017)

Resistance to organizational change Oreg (2006)

Job selection: Attraction-selectionattrition hypothesis

Selection as reoccurring everyday strategy

Carless (2005)

De Cooman et al. (2009)

Bolger and Schilling

(1991)

\section{Creation}

Purposefully creating new situations
Berg et al. (2013)

Tims et al. (2013)

Miles et al. (2002)

Spector and Fox (2002)
Extra Role Work Behaviors:

Organizational Citizenship Behavior and Counterproductive Work

Behavior 


\section{The Need for a Holistic View}

As argued throughout this paper, looking at I/O constructs and organizational behavior against the backdrop of the Person-Situation Navigation Mechanisms Framework is valuable for several reasons: 1) it puts these constructs and behaviors in an encompassing framework describing the multiple ways in which people engage with their work environment, 2) it explicates situation management as a series of intertwined strategies, with the direct implication that it is limiting to study isolated events, and 3) it shows that the situations we typically study in I/O psychology are often already impacted by several situation management strategies, which implies that those are no longer "pure situations", but already "person-situation interactions". In what follows, we will elaborate on each of those elements.

First, people are not just thrown into situations nor are they randomly exposed to them, but they actively influence, shape and (re)define the situations they experience (Rauthmann \& Sherman, 2016). By doing so, they engage with situations in multiple ways, through the application of one or multiple of the above-mentioned situation management strategies. In other words, situation management is the result of a continuous, complex interaction of both environmental factors and individual differences. Situation management is displayed in the selection, modification, evocation, creation, construction, or maintenance of the situations people experience. Accordingly, the Person-Situation Navigation Mechanisms Framework cannot and should not be interpreted as a rigid template that can simply be placed over situations and behaviors in the work context, but rather as a framework that aims to classify and interpret the complex processes and interactions in an overarching flow model. Rigorously implementing this practice could, in turn, help to connect seemingly unrelated theories and concepts and enable researchers to identify important yet neglected aspects of I/O research. Note also that both within and outside of the work context, individuals do not always have the opportunity to be actively involved in managing their experiences. Because the person-situation navigation mechanisms discussed here require some kind of (unintentional) activity on the individual's part, phenomena such as placement and layoffs do not fit within the framework. This of course does not negate the existence and importance of imposed behaviors and changes.

In addition, the situation management taxonomy by Rauthmann and Sherman (2016) explicates that the different person-situation interactions should be considered part of a flow model (see Figure 1). This is interesting because previous studies have typically studied specific situation management strategies in an isolated fashion, thereby creating a collection of seemingly unrelated and scattered events and findings. While studying work phenomena as isolated events is not an uncommon research practice, the situation management taxonomy by Rauthmann and Sherman (2016) implies that the research community could benefit from shifting towards a more interactive approach. So, instead of looking at situations as separate, independent occurrences, the framework acknowl- 
edges the ongoing dynamic interactions between persons and the environment. Such conceptualization of situations and events is of major interest to the I/O literature because an overwhelming amount of I/O research still zooms in on single work-related elements, thereby leaving large parts of the surrounding factors (e.g., events that led to the situation) unexplored. Picture an argument between two employees, for example. This particular argument may appear to be an isolated, single event at first glance. However - and this is where the Person-Situation Navigation Mechanisms Framework steps in - viewing the argument as an isolated event lacks context: the event (i.e., the argument) is preceded by numerous interactions, it is influenced by the respective predisposition of the participants, by their emotions and the environment they are in in that moment. Not including these factors and their dynamic interplay falls short of the complexity of the described event (i.e., the person-situation interaction). While researchers obviously cannot study all those factors simultaneously, research on work conflicts, team dynamics, and other interpersonal relations at work could benefit from acknowledging these interactions, thereby providing a more adequate and complete picture of the given circumstances. Not doing so might lead to incomplete or incorrect conclusions, which emphasizes the need to study behaviors and environments from a dynamic perspective, providing a more holistic view of the general picture.

Third, careful consideration of the interactions between people and the situations they encounter brings to light another common research practice with largely unnoticed implications. When examining the work environment, researchers need to be aware of the fact that a person's personality, values and goals are to some extent already factored into this environment. This is particularly true for $\mathrm{I} / \mathrm{O}$ researchers, where interventions mostly target the "objective situation" (as opposed to the psychological situation), or the objective, measurable work circumstances. However, there is a lot of person factors tailored into this "objective" work environment already. Think of an intervention to reduce stress levels of nurses, for example. People in this sample (i.e., nurses) would not have ended up in such a sample by chance, but rather have consciously chosen to be a nurse (i.e., job selection) or might have adapted some of the job characteristics already to align them with their own preferences (i.e., job crafting). This implies that this specific sample of nurses consists of individuals who already selected, modified, perceived, or avoided many situations in order to be(come) a nurse. Hence, it is a pipe dream that I/O psychologists can study situations independently from the individuals experiencing those situations outside of the lab. Researchers therefore need to consider that findings on the "objective situation" or the work environment (e.g., an intervention in order to reduce levels of stress) are impacted by person factors already, making it impossible for us to ever really examine the so-called "objective situation". Hence, empirical findings stemming from research on the work environment should be cautiously interpreted, knowing that when we study work situations, we study something that is affected already by the interaction of both person and situation factors. 
Lastly, the issues identified in this paper also clearly demonstrate one thing: We are only at the beginning of classifying work behaviors and phenomena into an overarching model such as the Person-Situation Navigation Mechanisms Framework. While we believe that the advantages of doing so would considerably benefit the research community, the points made here should be understood as "work in progress" and serve as initial food for thought. As we increasingly move towards a more holistic, dynamic perspective we will have to keep an open mind and continuously adjust, challenge and improve our ideas.

Funding: This work was supported by the Fonds Wetenschappelijk Onderzoek (FWO; Research Foundation Flanders) research fund [grant number FWOSB99].

Acknowledgments: The authors have no additional (i.e., non-financial) support to report.

Competing Interests: Theresa Leyens is the Editorial Assistant for PersonalityScience. However, she did not have access to this manuscript throughout the submission and has no decision-making power by virtue of her position within the journal.

Author Contributions: Theresa Leyens-Idea, conceptualization | Visualization (data presentation, figures, etc.) | Writing | Feedback, revisions. -Idea, conceptualization | Writing | Feedback, revisions | Supervision, mentoring. foeri Hofmans-Idea, conceptualization | Writing | Feedback, revisions | Supervision, mentoring.

Ethics Statement: The study was conducted in accordance with the ethical principles expressed in the Declaration of Helsinki. No explicit ethical approval was obtained as it was not required by local law (Canton of Vaud).

Related Versions: No other previously published versions of this manuscript exist in part or in whole.

\section{Supplementary Materials}

For this article Open-Peer Review is available via PsychArchives repository (for access see Index of Supplementary Materials below).

\section{Index of Supplementary Materials}

Personality Science. (Ed.). (2021). Supplementary materials to: Person-situation navigation mechanisms at work [Open peer-review]. PsychOpen GOLD.

https://doi.org/10.23668/psycharchives.5313 


\section{References}

Antonakis, J., Avolio, B. J., \& Sivasubramaniam, N. (2003). Context and leadership: An examination of the nine-factor full-range leadership theory using the Multifactor Leadership Questionnaire. The Leadership Quarterly, 14(3), 261-295. https://doi.org/10.1016/S1048-9843(03)00030-4

Bass, B. M., Avolio, B. J., Jung, D. I., \& Berson, Y. (2003). Predicting unit performance by assessing transformational and transactional leadership. The fournal of Applied Psychology, 88(2), 207-218. https://doi.org/10.1037/0021-9010.88.2.207

Berg, J. M., Dutton, J. E., \& Wrzesniewski, A. (2013). Job crafting and meaningful work. In B. J. Dik, Z. S. Byrne, \& M. F. Steger (Eds.), Purpose and meaning in the workplace (pp. 81-104). American Psychological Association. https://doi.org/10.1037/14183-005

Bolger, N., \& Schilling, E. A. (1991). Personality and the problems of everyday life: The role of neuroticism in exposure and reactivity to daily stressors. fournal of Personality, 59(3), 355-386. https://doi.org/10.1111/j.1467-6494.1991.tb00253.x

Carless, S. A. (2005). Person-job fit versus person-organization fit as predictors of organizational attraction and job acceptance intentions: A longitudinal study. Fournal of Occupational and Organizational Psychology, 78(3), 411-429. https://doi.org/10.1348/096317905X25995

Dalal, R. S. (2005). A meta-analysis of the relationship between organizational citizenship behavior and counterproductive work behavior. The Journal of Applied Psychology, 90(6), 1241-1255. https://doi.org/10.1037/0021-9010.90.6.1241

De Cooman, R., De Gieter, S., Pepermans, R., Hermans, S., Du Bois, C., Caers, R., \& Jegers, M. (2009). Person-organization fit: Testing socialization and attraction-selection-attrition hypotheses. Journal of Vocational Behavior, 74(1), 102-107.

https://doi.org/10.1016/j.jvb.2008.10.010

Denissen, J. J., Ulferts, H., Lüdtke, O., Muck, P. M., \& Gerstorf, D. (2014). Longitudinal transactions between personality and occupational roles: A large and heterogeneous study of job beginners, stayers, and changers. Developmental Psychology, 50(7), 1931-1942. https://doi.org/10.1037/a0036994

Edwards, J. A., \& Templeton, A. (2005). The structure of perceived qualities of situations. European fournal of Social Psychology, 35(6), 705-723. https://doi.org/10.1002/ejsp.271

Etzel, J. M., \& Nagy, G. (2021). Stability and change in vocational interest profiles and interest congruence over the course of vocational education and training. European fournal of Personality, 35(4), 534-556. https://doi.org/10.1177/08902070211014015

Frantz, A., \& Holmgren, K. (2019). The work stress questionnaire (WSQ)-reliability and face validity among male workers. BMC Public Health, 19(1), Article 1580. https://doi.org/10.1186/s12889-019-7940-5

Frederickx, S., \& Hofmans, J. (2014). The role of personality in the initiation of communication situations. Fournal of Individual Differences, 35(1), 30-37.

https://doi.org/10.1027/1614-0001/a000124 
Green, J. P., Dalal, R. S., Swigart, K. L., Bleiberg, M. A., Wallace, D. M., \& Hargrove, A. K. (2019). Personality consistency and situational influences on behavior. fournal of Management, 45(8), 3204-3234. https://doi.org/10.1177/0149206318781950

Hanna, A., Briley, D., Einarsdóttir, S., Hoff, K., \& Rounds, J. (2021). Fit gets better: A longitudinal study of changes in interest fit in educational and work environments. European fournal of Personality, 35(4), 557-580. https://doi.org/10.1177/08902070211014022

Judge, T. A., Simon, L. S., Hurst, C., \& Kelley, K. (2014). What I experienced yesterday is who I am today: Relationship of work motivations and behaviors to within-individual variation in the five-factor model of personality. The fournal of Applied Psychology, 99(2), 199-221. https://doi.org/10.1037/a0034485

Kandler, C., \& Rauthmann, J. F. (2021). Conceptualizing and studying characteristics, units, and fits of persons and environments: A coherent synthesis. European fournal of Personality. Advance online publication. https://doi.org/10.1177/08902070211048728

Kristof-Brown, A. L., Zimmerman, R. D., \& Johnson, E. C. (2005). Consequences of individuals' fit at work: A meta-analysis of person-job, person-organization, person-group, and personsupervisor fit. Personnel Psychology, 58(2), 281-342. https://doi.org/10.1111/j.1744-6570.2005.00672.x

LePine, J. A., Erez, A., \& Johnson, D. E. (2002). The nature and dimensionality of organizational citizenship behavior: A critical review and meta-analysis. The fournal of Applied Psychology, 87(1), 52-65. https://doi.org/10.1037/0021-9010.87.1.52

Lewin, K. (1946). Behavior and development as a function of the total situation. In L. Carmichael (Ed.), Manual of child psychology (pp. 791-844). John Wiley. https://doi.org/10.1037/10756-016

Lewin, K., Lippitt, R., \& White, R. K. (1939). Patterns of aggressive behavior in experimentally created "social climates". The fournal of Social Psychology, 10(2), 269-299. https://doi.org/10.1080/00224545.1939.9713366

McCrae, R. R., \& Costa, P. T. (1987). Validation of the five-factor model of personality across instruments and observers. Journal of Personality and Social Psychology, 52(1), 81-90. https://doi.org/10.1037/0022-3514.52.1.81

Miles, D. E., Borman, W. E., Spector, P. E., \& Fox, S. (2002). Building an integrative model of extra role work behaviors: A comparison of counterproductive work behavior with organizational citizenship behavior. International fournal of Selection and Assessment, 10(1-2), 51-57. https://doi.org/10.1111/1468-2389.00193

Minbashian, A., Wood, R. E., \& Beckmann, N. (2010). Task-contingent conscientiousness as a unit of personality at work. The fournal of Applied Psychology, 95(5), 793-806.

https://doi.org/10.1037/a0020016

Mischel, W., \& Shoda, Y. (1995). A cognitive-affective system theory of personality:

Reconceptualizing situations, dispositions, dynamics, and invariance in personality structure. Psychological Review, 102(2), 246-268. https://doi.org/10.1037/0033-295X.102.2.246

Mischel, W., \& Shoda, Y. (1998). Reconciling processing dynamics and personality dispositions. Annual Review of Psychology, 49(1), 229-258. https://doi.org/10.1146/annurev.psych.49.1.229 
Oreg, S. (2006). Personality, context, and resistance to organizational change. European fournal of Work and Organizational Psychology, 15(1), 73-101. https://doi.org/10.1080/13594320500451247

Rauthmann, J. F. (2012). You say the party is dull, i say it is lively: A componential approach to how situations are perceived to disentangle perceiver, situation, and perceiver $\times$ situation variance. Social Psychological \& Personality Science, 3(5), 519-528. https://doi.org/10.1177/1948550611427609

Rauthmann, J. F. (2021). Capturing interactions, correlations, fits, and transactions: A PersonEnvironment Relations Model. In Rauthmann, J. F. (Ed.), The handbook of personality dynamics and processes (pp. 427-522). Academic Press. https://doi.org/10.1016/B978-0-12-813995-0.00018-2

Rauthmann, J. F., \& Sherman, R. A. (2016). Situation change: Stability and change of situation variables between and within persons. Frontiers in Psychology, 6, Article 1938. https://doi.org/10.3389/fpsyg.2015.01938

Rauthmann, J. F., \& Sherman, R. A. (2020). The situation of situation research: Knowns and unknowns. Current Directions in Psychological Science, 29(5), 473-480. https://doi.org/10.1177/0963721420925546

Rauthmann, J. F., Sherman, R. A., \& Funder, D. C. (2015). New horizons in research on psychological situations and environments (Rejoinder to target article). European fournal of Personality, 29, 382-432.

Schaufeli, W. B. (2017). Applying the job demands-resources model. A 'how to'guide to increase work engagement and prevent burnout. Organizational Dynamics, 46(2), 120-132. https://doi.org/10.1016/j.orgdyn.2017.04.008

Sherman, R. A., Nave, C. S., \& Funder, D. C. (2010). Situational similarity and personality predict behavioral consistency. Journal of Personality and Social Psychology, 99(2), 330-343. https://doi.org/10.1037/a0019796

Skogstad, A., Einarsen, S., Torsheim, T., Aasland, M. S., \& Hetland, H. (2007). The destructiveness of laissez-faire leadership behavior. Journal of Occupational Health Psychology, 12(1), 80-92. https://doi.org/10.1037/1076-8998.12.1.80

Spanouli, A., \& Hofmans, J. (2016). Walking the tightrope: Counterproductive work behavior as compensation for citizenship demands. Frontiers in Psychology, 7, Article 1530. https://doi.org/10.3389/fpsyg.2016.01530

Spector, P. E., \& Fox, S. (2002). An emotion-centered model of voluntary work behavior: Some parallels between counterproductive work behavior and organizational citizenship behavior. Human Resource Management Review, 12(2), 269-292. https://doi.org/10.1016/S1053-4822(02)00049-9

Spector, P. E., \& Fox, S. (2010). Counterproductive work behavior and organisational citizenship behavior: Are they opposite forms of active behavior? Applied Psychology, 59(1), 21-39. https://doi.org/10.1111/j.1464-0597.2009.00414.x

Tett, R. P., \& Burnett, D. D. (2003). A personality trait-based interactionist model of job performance. The fournal of Applied Psychology, 88(3), 500-517. https://doi.org/10.1037/0021-9010.88.3.500 
Tett, R. P., Toich, M. J., \& Ozkum, S. B. (2021). Trait activation theory: A review of the literature and applications to five lines of personality dynamics research. Annual Review of Organizational Psychology and Organizational Behavior, 8, 199-233. https://doi.org/10.1146/annurev-orgpsych-012420-062228

Tims, M., Bakker, A. B., \& Derks, D. (2013). The impact of job crafting on job demands, job resources, and well-being. Journal of Occupational Health Psychology, 18(2), 230-240. https://doi.org/10.1037/a0032141

van Vianen, A. E. (2018). Person-environment fit: A review of its basic tenets. Annual Review of Organizational Psychology and Organizational Behavior, 5, 75-101. https://doi.org/10.1146/annurev-orgpsych-032117-104702

Wanberg, C. R., \& Banas, J. T. (2000). Predictors and outcomes of openness to changes in a reorganizing workplace. The fournal of Applied Psychology, 85(1), 132-142. https://doi.org/10.1037/0021-9010.85.1.132

Wille, B., \& De Fruyt, F. (2014). Vocations as a source of identity: Reciprocal relations between Big Five personality traits and RIASEC characteristics over 15 years. The fournal of Applied Psychology, 99(2), 262-281. https://doi.org/10.1037/a0034917

Wrzesniewski, A., \& Dutton, J. E. (2001). Crafting a job: Revisioning employees as active crafters of their work. Academy of Management Review, 26(2), 179-201. https://doi.org/10.2307/259118

Xanthopoulou, D., Bakker, A. B., Demerouti, E., \& Schaufeli, W. B. (2007). The role of personal resources in the job demands-resources model. International fournal of Stress Management, 14(2), 121-141. https://doi.org/10.1037/1072-5245.14.2.121

Zhang, F., \& Parker, S. K. (2019). Reorienting job crafting research: A hierarchical structure of job crafting concepts and integrative review. Journal of Organizational Behavior, 40(2), 126-146. https://doi.org/10.1002/job.2332

Ziegler, M., Horstmann, K. T., \& Ziegler, J. (2019). Personality in situations: Going beyond the OCEAN and introducing the Situation Five. Psychological Assessment, 31(4), 567-580. https://doi.org/10.1037/pas0000654

\section{eapp}

Personality Science (PS) is an official journal of the European Association of Personality Psychology (EAPP).
(4) leibniz-psychology.org

PsychOpen GOLD is a publishing service by Leibniz Institute for Psychology (ZPID), Germany. 